\title{
LOS CÓMICS EN LA CONSTRUCCIÓN DE LA PROPUESTA EDUCATIVA EN EL PRIMER FRANQUISMO
}

\section{The comics in the construction of the educational proposal in the first francoism}

\author{
José Carlos SANCHIDRIÁn FernÁndeZ \\ Universidad de Valladolid \\ Correo-e: jcfersan@uva.es
}

Recepción: I9 de febrero de 2019. Envío a informantes: 5 de marzo de 2019 Aceptación definitiva: Is de julio de 2019

Resumen: En los años posteriores a la finalización de la Guerra Civil I936-1939, España tuvo que asumir las consecuencias dramáticas producidas por la insurrección. Debió enfrentarse no solo a la crisis de identidad de las dos Españas, sino al mantenimiento de un orden basado en el autoritarismo de corte fascista. La educación de niños y jóvenes constituyó uno de los esenciales argumentos en los que se apoyó el Gobierno de la nación para desplegar toda una política de adoctrinamiento compresivo y homogenizante que asegurase la llamada "paz social». Los cómics que aparecieron en esos años fueron uno de los instrumentos para la educación no formal de la población escolar.

Palabras clave: educación infantil; cómics; censura franquista; posguerra.

Авstract: The years after the end of the 1936-1939 Civil War, Spain had to assume the dramatic consequences produced by the insurrection. He had to face not only the identity crisis of the two Spains but also the maintenance of an order based on fascist authoritarianism. The education of children and young people was one of the essential arguments in which the Government of the nation was supported to deploy a comprehensive and homogenizing policy of indoctrination to ensure the so-called «social peace». The comics that appeared in those years was one of the instruments for non-formal education of the school population.

KEY WORD: education; comics; francoist censorship; postwar. 


\section{Introducción}

$\mathrm{N}$

ADA Más CONCLUIR EL CONFLICTO ARMADo, la superioridad, imposible de ser contrarrestada, del bando faccioso emprendió una tarea de reconstrucción unidireccional de todos los órganos de gestión y administración del Estado. Se hizo de tal manera para que esta no diera lugar a equívocos. Los vencedores narran la historia y proponen el régimen de vida para ellos mismos y para los vencidos.

En un país fracturado, con una economía deprimida y unas condiciones de vida que habían retrocedido a tiempos pretéritos, se planteó la ingente tarea de rehacer toda la estructura del Estado siguiendo una línea que contaba con el soporte del nacionalcatolicismo. Entre los años de 1939 al I959, la autarquía impregna todos los planos de vida y relación de la ciudadanía. A la población se le hace llegar una propuesta basada en dos ideas fuerza: ensalzar los valores patrios y ocultar los referentes republicanos o foráneos. En ese interés, la educación y la escuela son tomados como un instrumento de excepcional importancia para generar una nueva España y un nuevo español en el que la discrepancia no era contemplable. El control se extiende ramificadamente a todos los ámbitos y todos los agentes educativos, formales e informales, deben ser objeto de acción y sujetos de supervisión.

Es posible que analítica o intuitivamente se entendiera, por parte de los gobernantes, que las formas represivas tienen un efecto limitado en el tiempo pero que, para el largo plazo, los cambios deberían asentarse mediante una estricta supervisión de la infancia y la juventud. La escuela adoctrinaba, pero la «calle» no podía alejarse o contradecir esa narrativa, de ahí que las historietas, los tebeos o cualquier publicación destinada a los más jóvenes fuera escrutada con ojos censores.

El objeto de este trabajo es presentar esta perspectiva; es abrir una visión en la que, lejos de suponer que la construcción del nuevo Estado y la «pax social» fuera una tarea de superación de las coyunturas (que se presentaban el final de la guerra), constituyó una idea-acción perfectamente instrumentada, para la que se puso toda la potencia del Estado a su servicio.

\section{Lo imaginado de la historia real}

Las grandes dinámicas sociales que surgen como consecuencia del conflicto se caracterizan porque el régimen emergente impone al grupo perdedor la asunción de los valores, usos y costumbres propios del grupo vencedor. La casuística que opera en este sentido nos permite desentrañar con mayor precisión la secuencia de acontecimientos.

El movimiento social derivado del enfrentamiento entre grupos rivales pone de manifiesto que cuanto más alejado se está de las formas de vida y de las creencias, la forma de reposicionamiento será mucho más erosiva, más dura, más drástica y, si cabe, más brutal. Sin embargo, proyectar una sociedad hacia el futuro no puede 
LOS CÓMICS EN LA CONSTRUCCIÓN DE LA PROPUESTA EDUCATIVA

EN EL PRIMER FRANQUISMO

JOSÉ CARLOS SANCHIDRIÁN FERNÁNDEZ

hacerse sin restañar las grandes fracturas sociales generadas como consecuencia del hecho conflictivo. La reparación que se hace no tiene rasgos conmiserativos, sino que se emprende como acción de ajuste y a la que su despliegue puede atribuírsele dos efectos. Por un lado, se persigue evitar que se realimente la acciónreacción conflictiva y, por otro, se trata de que el sentimiento «perdedor» pueda ser enjugado sin que ello constituya para sus portadores la pérdida total y efectiva de todo el colectivo para la vida civil. Por estas razones, a la fase inicial, dotada de un claro matiz represivo y violento, generalmente le sigue otra en la que se trata de ir amortiguando la colisión con propuestas más asequibles, presentada mediante objetos facilitadores, posibles, para ir propiciando el desplazamiento ideológico hacia los contenidos centrales de quienes en ese momento ejercen el poder sin ambages, sin que ello suponga una torsión inasumible para los derrotados.

El mecanismo social que se propone, inscrito bajo el signo de la eficacia -el tiempo es un factor irrenunciable- consiste en que en el medio y largo plazo se presente un cuadro con opciones de valores cimentado sobre los ideales del grupo ganador, pero asequible al grupo perdedor. Así, todo el campo de acción ${ }^{1}$ se segmenta y una vez dividido se encarga a agentes especialistas su transformación.

Los acontecimientos sociales que pudieran ser objetivables a través de la mirada aséptica de un «teórico» observador imparcial serían los elementos centrales en la construcción de la verdad histórica, no obstante, cuando una parte de esos acontecimientos no son asumibles por grupos pervivientes y «necesarios» en el nuevo tejido social emergente se traiciona y se resignifica el discurso mediante una nueva narrativa, en la que el pasado es una realidad imaginada. De manera imperiosa los hechos con valor en la configuración del «ethos» deben ser modificados, recontados con una nueva narrativa en la que se filtre y se depure aquello que pudiera ser considerado un contravalor. Desde una parte se trabaja sobre los ideales de familia; otros, sobre la religión (única) o sobre la educación, produciendo ámbitos de significaciones colectivas que enmarcan un nuevo imaginario social, interpretado en el sentido en el que fue propuesto por Castoriadis ${ }^{2}$ en el campo de las ciencias sociales. Ese imaginario al que se refiere conecta el mecanismo por el cual el individuo que inventa un (su) mundo, simultáneamente se modifica a sí mismo. Se transforma a la vez que cambia el entorno en el que se encuentra. Para Castoriadis podría decirse que se trata de la recreación sociohistórica y psíquica de figuras, formas e imágenes que dotan de contenidos significativos a otras estructuras de la sociedad.

En el fondo se actúa tratando de dar coherencia al sistema, dado que sin coherencia no hay seguridad, sin coherencia no hay previsibilidad y cualquier respuesta que aparezca entre los límites de lo obvio y de lo aceptable tanto en lo grupal como en lo individual debe tratarse como parte de la cadena de acción de respuestas vinculadas.

Weber, M.: Economía y Sociedad, México, Fondo de Cultura Económica, 1996, p. 5.

Castoriadis, C.: La institución imaginaria de la sociedad, Barcelona, Tusquets Editores, 1975 (Colección Acracia). 
Carretero Pasín ${ }^{3}$ nos proporciona una interesante visión ampliatoria cuando denomina a la construcción imaginaria «fantasía socialmente solidificada», que permite entender la reinterpretación de la realidad social a partir de la construcción de la virtualidad imaginaria que recrea.

La historia podría estar construida de realidades imaginarias solidificadas en función del mantenimiento de la hegemonía de los ganadores y de la supervivencia de los perdedores. En este sentido, para nada resultaron banales los acontecimientos previos y posteriores a la insurrección de 1936. El territorio nacional se fraccionaba en aquellos años y la desagregación encontraba muchas más causas que motivos para la construcción cooperativa de las «Españas». El resultado interpretable -incluso al margen de los números- deja dos bandos y crea dos bandos. La España plural y diversa, desde los aspectos social, económico y organizativo, bajo el imperio de las armas, se aplasta y se comprime en dos: vencedores-victoriosos y derrotados-perdedores. En medio de los bloques se entronizan el miedo, la prevención y el sentimiento perdedor, que no dejan entrever un atisbo que permita adivinar mejoras a corto plazo u horizontes esperanzadores en los tiempos próximos. Aun así, la vida continúa en las ciudades y en el campo. Antes guerra, hambre y ahora miedo. Como a veces se ha dicho urge desprenderse del sentimiento de pérdida. Moreno Julia y Vilanova Ribas ${ }^{4}$ escriben:

A partir de 1939 en España las grandes mayorías debieron comerse su propia identidad o su pasado inmediato. Por temor, por la ausencia de canales adecuados, y por la censura, la vivencia de la República o de la Guerra Civil no la trasmitieron a sus hijos por lo que el franquismo, además atomizó toda clase social. La España democrática se funda sobre los cimientos de esa represión, uno de cuyos rasgos más sobresalientes es el silencio y el terror impuesto a los vencidos.

El conflicto de I936-I939 supuso que España desde la perspectiva demográfica, industrial y cultural quedara devastada y que los valores del grupo perdedor fueran arrasados. El Estado emergente (inicialmente aislado en la Sociedad de Naciones) reconocía dos objetivos en el horizonte inmediato. El primero consistía en la superación de la solución autárquica tomada en el primer momento. El Gobierno insurrecto sabía que no era más que una falsa salida para el aislamiento en el que se había colocado en razón de la ilegalidad del régimen emergente, que agrandaba el deterioro económico y lentificaba la reconstrucción de las infraestructuras. España necesitaba imperiosamente ser reconocida. Por otra parte, el deterioro de las clases trabajadoras, sustentadas básicamente en los jornaleros con baja cualificación, resultaba una opción inviable, incompatible con cualquier incorporación al trabajo industrial o al militar. Se necesitaba combatir el analfabetismo. El Estado

\footnotetext{
Carretero Pasín, A. E.: «Lineamientos para una aproximación al imaginario social. Imaginario», São Paulo, v. I2, n. I2. Extraído de: http://pepsic.bvsalud.org/scielo.php?script=sci_ arttext\&pid=SI413-666X200600oIooor9\#ar el I7 marzo 2019 .

4 Moreno Julia, F. X. y Vilanova Ribas, M.: Atlas de la evolución del analfabetismo en España de 1887 a 1981, Madrid, Secretaría General Técnica. Centro de Publicaciones. Ministerio de Educación y Ciencia, I990, p. 6.
} 
quería convertir a España (grande y libre) en un solo Estado de naciones, amplio, común, acogedor (paz y trabajo) y para ello debía facilitar una idealización (más destinada al consumo interno que a argumentar su situación internacionalmente) estereotipada del mundo en la que el progreso fuera el horizonte que guiara todas las acciones. Se narró (propaganda y publicidad) que España no era una isla, un eslabón perdido en el occidente, al margen de la sociedad internacional, sino un centro de valores -una reserva de Occidente- y una parte imprescindible del mundo forjada a través de la memoria del imperio.

Desde los organismos más ideologizados del nuevo Régimen se conocía la urgencia para llevar a cabo la «normalización» social y productiva. Entre las prioridades había que recomponer la pirámide poblacional, claramente desequilibrada, y para ello se confió en la familia. La familia apareció de pronto como la tabla salvadora para cimentar las expectativas de futuro. El grupo familiar que la República había conectado con su tiempo fue invalidado. Para sustituirlo se creó otro organizado a semejanza del nuevo Estado y perfilado por las combativas directrices de la Iglesia católica. Se le asignó el fin de tener hijos para Dios y la patria. La familia, núcleo y germen del nuevo tejido social que vive en constante estado de precariedad, necesita ser salvada de sus circunstancias para que pueda cumplir con el objetivo marcado. El apoyo a la familia es urgente, y así, las políticas públicas destinadas a esta comienzan a ser efectivas incluso antes de la conclusión del conflicto armado. Coincidiendo con el segundo aniversario de la insurrección (I8 de julio de 1938) ya se dicta una primera norma (Ley de subsidios familiares) destinada a la protección de la familia. En el preámbulo de la Ley se dice: «Es consigna rigurosa de nuestra Revolución elevar y fortalecer la familia en su tradición cristiana, sociedad natural perfecta y cimiento de la Nación».

Es obvio que todo el esfuerzo económico era absorbido por la situación bélica, pero se acudió a la ingeniería económico-social para crear un organismo que canalizara los objetivos y proveerlo de fondos. El resultado fue la aparición en el panorama político de la Caja Nacional de Subsidios. En el número 513 correspondiente a 1949, en la publicación del Instituto Nacional de Previsión se dice:

Respondiendo a esta exigente necesidad, la Base Quinta de la Ley creadora del Régimen, encomendó al Instituto Nacional de Previsión, la organización, con separación completa de sus demás funciones, bienes y responsabilidades, de la Caja Nacional de Subsidios Familiares, que habría de comprender obligatoriamente a todos los patronos y asegurados, afectados por el Régimen.

La fundación se hace con cinco millones de pesetas aportados por el Estado, provenientes del saldo resultante del Servicio Nacional del Trigo. Pero su apoyo no decayó una vez estabilizado el nuevo régimen, sino que se le continuó dando una decidida protección según queda reflejado en las cifras de variación del subsidio que percibían las familias en función del número de hijos.

El porcentaje de variación en función del número de hijos es 2,79 veces mayor para las familias de doce hijos frente a las de dos, cuando, si ya se había considerado un incremento para ajustarlo en el tiempo, lógico hubiera sido pensar que en 
razón del número de descendientes el incremento debería de ser lineal. La resultante, independientemente de lo declarado en los fundamentos de la subvención, es una clara decantación hacia la familia con alta tasa reproductiva, como queda de manifiesto en la siguiente tabla:

TABLA I

\begin{tabular}{|l|c|c|c|}
\hline \multicolumn{4}{|c|}{ Prestaciones o beneficios: } \\
\hline & Pesetas al mes 1939 & Pesetas al mes 1950 & Porcentaje de variación \\
\hline Por 2 hijos & I5 & 40 & 266,67 \\
\hline Por 3 hijos & 22,5 & 65 & 288,89 \\
\hline Por 4 hijos & 30 & 90 & 300,00 \\
\hline Por 5 hijos & 40 & I20 & 300,00 \\
\hline Por 6 hijos & 50 & 160 & 320,00 \\
\hline Por 7 hijos & 60 & 280 & 466,67 \\
\hline Por 8 hijos & 75 & 400 & 533,33 \\
\hline Por 9 hijos & 90 & 540 & 600,00 \\
\hline Por Io hijos & I05 & 700 & 666,67 \\
\hline Por II hijos & I25 & 880 & 704,00 \\
\hline Por I2 hijos & I45 & 1.080 & 744,83 \\
\hline
\end{tabular}

Fuente de datos: Instituto Nacional de Previsión. Elaboración propia.

Nótese que en ese incremento no solo se contempla lo que pudiera considerarse lógico incremento en función de la variable temporal. No, entre sus líneas deja verse el aliento y la motivación a la función reproductiva de las familias. Parece entenderse que con una prole numerosa se sirve a Dios y al Estado, aunque las circunstancias económicas sean precarias. Cabe preguntarse si los ideólogos del régimen (fundamentalmente la Iglesia católica) tenían entre sus objetivos acercar a la familia española a las tasas de la fecundidad natural que tan apreciada era entre las familias huteritas.

La importancia de la subvención queda manifiesta si la comparamos con los ingresos regulares que podían obtenerse por el trabajo. Según Villar Salinass, tomando como referencia el salario medio efectivo, al día de los españoles, durante el año I943 era (trabajadores cualificados) de I6,95 pesetas y de I2,63 (no cualificados). Para 1950 esos salarios se habían incrementado notablemente, llegando de media hasta 25,23 pesetas (27,32 pesetas para los trabajadores cualificados y 20,12 para los no cualificados).

Unos años más tarde, la vida económica de las familias dependientes de la renta de trabajo vio notablemente mejorada su situación. En el año i95o, el salario

S Villar Salinas, J.: «Repercusiones demográficas de la última guerra civil española, problemas que plantean y soluciones posibles, 1942 Madrid (Memoria premiada por la Real Academia de Ciencias Morales y Políticas en el bienio 1937-1938)», en Carreras, Albert y Tafunel, Xavier (coords.): Estadísticas históricas de España Siglos XIX-XX. Madrid, Fundación BBVA, 2005. 
LOS CÓMICS EN LA CONSTRUCCIÓN DE LA PROPUESTA EDUCATIVA

EN EL PRIMER FRANQUISMO

JOSÉ CARLOS SANCHIDRIÁN FERNÁNDEZ

medio mensual se elevó a 756,90 pesetas, al que se podrían añadir 40 pesetas más si la familia tenía dos hijos, pero si ese mismo trabajador tenía i2 hijos el salario quedaría ampliamente superado por la subvención de i.o8o pesetas. No se actuaba planificadamente, pero la intuición económica de esa familia media, que debía comprar cara la harina y la leche y que a la vez tenía salarios bajos, encontraba un factor de corrección económica en los hijos, lo que coincidía «mágicamente» con la intención repobladora del Gobierno.

Aun así, y por si la acción económica sustentada por la política de subvenciones no era lo suficientemente convincente, se tomaron otras medidas de carácter propagandístico que animaba a otras familias a competir en cuanto a proles numerosas.

El Instituto Nacional, basándose en un Decreto de 22 de febrero de 1941, instituyó los premios de natalidad. Este reconocimiento dejaba nítidamente asentado el esfuerzo repoblador que se pedía a las familias españolas, como se decía en la publicación del propio Instituto:

La prole numerosa es beneficio inmenso que la familia presta a la sociedad; por eso es justo que la sociedad premie y estimule a quienes con gran sacrificio levantan la excepcional carga familiar.

Esas familias, con proles hiperbólicas, prestaban un servicio adicional al Estado. Eran utilizadas como el ejemplo a seguir y en razón de su mérito procreador y de la afección al Régimen eran recibidas en el Palacio del Pardo por el jefe del Estado, hecho recogido por todos los medios de comunicación social.

\section{Escalar la pirámide de población}

La efectividad de las medidas (económicas a cargo del Estado e ideológicas a cargo de la Iglesia) consiguió reactivar el crecimiento poblacional. La tasa de crecimiento (por mil habitantes), según los datos de censo publicados por el INE (Instituto Nacional de Estadística), se sitúa entre los años 1941 y i950 en el 7,8r; para el período de I95I a I960 la tasa era ya del 8,44 y del Io,42 para la década siguiente. El ritmo de crecimiento proporcionó un incremento de población que entre 1940 y 1970 fue de 7.941.623 personas.

Parece indiscutible que con la recomposición de la pirámide poblacional (medida que constituyó una de las primeras acciones emprendidas por el Gobierno presidido por el jefe del Estado F. Franco) se consiguió también redefinir el marco de relaciones de las familias patriarcales y asimétricas con una rejerarquización de los papeles sociales de la relación y redefinir los objetivos que deben cumplir las uniones de hombres y mujeres. A esta tarea se sumó con toda su potencia de ideologización la Iglesia católica. Las medidas dieron como consecuencia que la población infantil sufriera una notable variación, según se muestra en el siguiente gráfico: 
GRÁFICO I

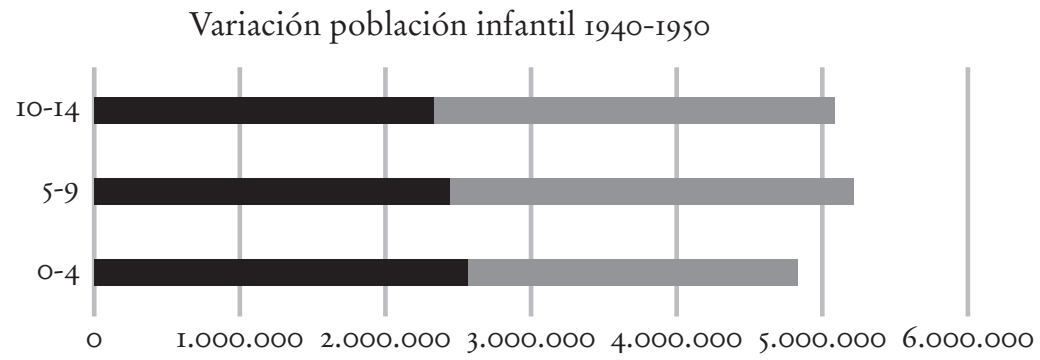

\begin{tabular}{r|c|c||c||} 
& $0-4$ & $5-9$ & IO-I4 \\
\hline Total año I950 & 2.572 .406 & 2.434 .633 & 2.326 .752 \\
\hline Total año I940 & 2.258 .210 & 2.77 I.46I & 2.752 .893 \\
\hline \hline
\end{tabular}

Total año $1950 \square$ Total año 1940

El aumento de la población infantil, como consecuencia de una acción planificadora, exige de los Estados mayores dotaciones económicas. Son específicamente grupos que consumen recursos económicos y dotacionales, pero quizá los ideólogos del «Nuevo Régimen» no estaban de acuerdo con esta interpretación de la macroeconomía.

El primer presupuesto que se elaboró por parte del Gobierno de Franco data de 1940. Para ese año la suma prevista fue a situarse en torno a 7.160 millones de pesetas. Se trata de una cifra importante para una economía que acababa de salir de una guerra y que necesitaba una urgente y total tarea de reconstrucción. Sería fácil imaginar, desde el punto de vista del objetivo a conseguir y de la racionalidad económica, cuál sería la prioridad de los gastos. No fue así. La euforia victoriosa y los compromisos adquiridos determinaron el orden. Primero, pagar los atrasos de la guerra; luego, subir el sueldo a los militares (y algunos funcionarios); mantener la maquinaria bélica mediante la compra de material para el ejército; pagar a la Iglesia, alguna parte (no muy cuantiosa) destinada a la obra pública de reconstrucción (imprescindible para volver a poner en marcha las comunicaciones con las que surtir a la industria), y, en último lugar, el capítulo social, con escasa previsión para el gasto en pensiones, sanidad o educación.

\section{Maestros para la escuela}

La realidad educativa era en extremo árida y desoladora. Afortunadamente seguía en pie una gran parte de las infraestructuras educativas hechas en el período republicano, pero el cuerpo nacional de maestros, agente educativo imprescindible, tenía ausencias importantes. Ese déficit no tenía posibilidad de ser cubierto ni ser obviado o sustituido, dado que la tarea educativa (estratégica para la construcción 
LOS CÓMICS EN LA CONSTRUCCIÓN DE LA PROPUESTA EDUCATIVA

EN EL PRIMER FRANQUISMO

JOSÉ CARLOS SANCHIDRIÁN FERNÁNDEZ

del futuro) tenía que ser cubierta desde la exigencia de afección al Nuevo Régimen y una importante cifra de los maestros ejercientes durante la República habían sido "depurados o exiliados» ${ }^{6}$, ante la menor sospecha o atisbo de ideas de izquierdas o republicanas. En el mismo sentido, Navarro Saladrinas ${ }^{7}$ escribe:

Tras las primeras y masivas destituciones, tras los cadáveres de los maestros fusilados por tener un carnet de la FETE, vino el escrupuloso proceso de depuración de todos y cada uno de los cincuenta mil maestros nacionales españoles.

El número de maestros que constaba en el Escalafón del Magisterio, según los datos que obran en el MEC, alcanzaba la cifra de 50.527 (número estimado por Navarro Saladrinas citando a Ibáñez Martín) ${ }^{8}$. De ellos un 30\% fue apartado de la enseñanza a través de los expedientes disciplinarios, privando a la escuela no solo de una parte importante de buenos maestros y excelentes profesionales, sino que también se cercenó la representación, en la institución educativa, de algunos pertenecientes a las vanguardias pedagógicas y a otros que presentaron cualquier disidencia con las orientaciones convenientes al «orden social» de 1936.

Gutiérrez López ${ }^{9}$ recoge unas palabras de Pedro Sainz Rodríguez ${ }^{10}$ (ministro de Educación) en las que se manifiesta el sentir que habría de instrumentar el nuevo magisterio:

[...] recomendaba a los maestros que, teniendo en cuenta el montón de muertos que tenemos ante nuestra vista y la sangre derramada sería motivo más que suficiente para que aquellos que tuviesen un resto de error en el pasado en el fondo de sus conciencias, se incorporen llenos de entusiasmo a los nuevos dogmas de la Patria.

En una España llena de ausencias, tanto de cuadros profesionales como de productos básicos, al cuerpo de Maestros se le fija en 1940 un salario anual cercano a las 3.000 pesetas (aprox. 250 pesetas/mes), lo que comparativamente con el salario de profesionales cualificados (5ro pesetas) hacía evidente la desconsideración que «el Nuevo Régimen» otorgaba a este colectivo y a su trabajo. Entre I940 y 1950 el salario se incrementó en un $240 \%$, con lo que se logró disminuir el diferencial con los salarios medios de personal cualificado, recuperando en parte la dignidad salarial ${ }^{\text {II }}$.

6 Juliá, S.: «Edad Contemporánea», en Valdeón, J.; Pérez, J. y Juliá, S., Historia de España, Madrid, Espasa Calpe, 2003.

7 Navarro Saladrinas, R.: «El franquismo, la escuela y el maestro (1936-1975)», Historia de la Educación: Revista Interuniversitaria, Salamanca, n. 8 (1989), p. I7I.

8 Ibáñez Martín, J. A.: io años de servicios a la cultura española; sin datos.

9 Gutiérrez López, A.: «Educación y depuración docente en el primer franquismo», Temas para la Educación, n. ${ }^{\circ}$ Io. Revista digital para profesionales de la enseñanza 20Io, Federación de enseñanza de cc. oo. Andalucía, p. 3.

10 Discurso pronunciado en junio de 1938 ante maestros y maestras asistentes al Curso de orientaciones nacionales de Enseñanza Primaria en Pamplona.

II En el período 193I-I936, en el que las Escuelas Normales se convierten en Centros de Enseñanza Profesional -inicial y permanente-, con especializaciones en la carrera de Magisterio y rango 
Es lícito pensar que la decisión que tomó una gran parte de los maestros de permanecer en las tareas educativas, incluso aceptando el alejamiento ${ }^{\mathrm{I2}}$, tuviera su origen en el conjunto de condiciones (económicas y sociales) que el franquismo vivía en sus primeros años de existencia. La regularidad de ingresos, garantizada por el Estado, hizo que fueran consideradas como aceptables unas malas condiciones laborales, en la medida que estas conseguían asegurar una forma de estar (reconocimiento social) en la nueva sociedad y una forma de salvaguardar el sustento.

Se sabía que después de las «purgas» se había concedido permiso para seguir ejerciendo en el magisterio a profesionales sobre los que se tenían dudas en cuanto a la filiación ideológica ${ }^{13}$, pero que eran imprescindibles para atender a una población infantil que necesitaba ser educada e instruida (recogida) en los estrictos márgenes del pensamiento reaccionario guiado por la estrecha visión de la moralidad católica.

Cuando se dicta el 17 de julio de 1945 la Ley de Enseñanza Primaria se deshace el, hasta entonces, vigente modelo creado para la configuración ideológica de la enseñanza. La pugna de influencias conformada por el partido falangista y la Iglesia católica se decanta a favor de la vertiente más retrógrada y moralizante surgida con posterioridad a la publicación de la encíclica de Pío XII Divini illius magistri, en la que se reconoce a la Iglesia un papel fundamental para la educación incluso por encima del Estado ${ }^{14}$. El control es suyo y lo ejerce proponiendo y examinando los textos, los programas de las acciones educativas. Sobre los maestros y sobre el diseño de materias que serían objeto de enseñanza se tuvo el cuidado suficiente para que no se produjeran desviaciones.

Para los maestros la constricción ideológica y el bajo sueldo no eran solo las condiciones básicas para el ejercicio de la profesión, había que sumar a esas condiciones de trabajo otras razones técnicas y de infraestructura docente. La ratio de niños de 5 a I4 años (la enseñanza primaria establecida en la ley de 1945 fijaba un ciclo de los 6 a los I2 años -ampliado hasta los I4 en I964- que luego fue ampliada hasta los I4 en I964) por maestro en I940, se aproximaba a I53. En esta cifra hay que considerar que, a pesar de la obligatoriedad de asistir a la escuela (cuyo cuidado

universitario. El acceso al ejercicio de la profesión es directo para los que aprueban el año de prácticas y el examen final, percibiendo un sueldo de 4.000 pesetas anuales (I.00o pesetas más de lo que era habitual en el Magisterio Nacional) [Román SÁNchez, José María y Cano González, Rufino: La formación de maestros en España (I838-2008): necesidades sociales, competencias y planes de estudio, Universidad de Valladolid, 2008].

${ }_{12}$ Los sancionados con suspensión y traslado de localidad fueron 2.273 (9,62\%) según MoRENTE VALERo, Francisco: «La depuración franquista del magisterio público. Un estado de la cuestión», Hispania, LXI/2, núm. 208 (200I).

${ }_{13}$ Fernández Soria, J. M. y Agullo Díaz, M. ${ }^{a}$ C.: «La depuración franquista del magisterio primario", Historia de la Educación, Ediciones Universidad de Salamanca (I997), n. ${ }^{\circ}$ I6. file:///C:/ Users/Carlos/AppData/Local/Temp/oo8r991oor59-I.pdf. Extraido el I2 de enero de 2019.

${ }_{14}$ Por acuerdo con la Santa Sede, en I94I se reestablecen algunos artículos del Concordato de I85i. Se recupera el núm. 2 por el que la enseñanza en universidades, colegios, seminarios y escuelas públicas será de acuerdo con la doctrina de la religión católica -acuerdo 2-, permitiéndose a los prelados la vigilancia en cuestiones de fe, incluso en las escuelas públicas. 
correspondía a los alcaldes), muchos niños no asistían o lo hacían solo a intervalos, según lo permitieran las circunstancias de ayuda al sustento de las familias. Otro mundo separado de la escuela nacional se abría al importante número de alumnado que era escolarizado en los centros regidos por las órdenes religiosas. Viñao Frago $^{15}$ nos proporciona un dato significativo. El alumnado de más de ro años inscrito hasta 1940 en instituciones privadas (entre ellas las religiosas) era del 8,3\% del total, para el curso 1940-194I la cifra se eleva hasta el 61,5\%. El nuevo régimen ya había eliminado a todas aquellas instituciones de enseñanza que no tuvieran adscripción a una orden religiosa (Orden de 5 de mayo de 1942 para la nacionalización de las escuelas privadas) por lo que la totalidad de ese alumnado fue educada doctrinariamente en el catolicismo, teniendo en cuenta además que entre docentes en la educación primaria no era frecuente la condición de maestro y que fueron de notable importancia en los entornos urbanos.

Esa fue la escuela que llevó a cabo una magna operación destinada a garantizar la instrucción básica y la homogeneización de ideas. Por una parte, asegurándose el silencio de los adultos disidentes, cualquiera que fuera su lugar y posición, a través de las más simples y directas normas represivas, llevadas a cabo por las fuerzas de orden público, lo que imposibilitaba que en los domicilios familiares fuera contradicha cualquier enseñanza trasmitida al pensamiento infantil por los agentes educativos oficiales. Por otra parte, se trató de ganar el futuro haciendo llegar la idea compacta que transmitía el nacionalcatolicismo franquista a la formación de los niños. Para el largo plazo, a la educación se le ofreció un papel relevante en el nuevo enclasamiento. En ese proyecto de futuro se contaba con una transformada escuela atendida por maestros regulados y supervisados y con la Iglesia dotada con el indiscutible papel de garante del orden y la moral, que no titubeó en transferir el decisivo encargo a las manos de las órdenes, congregaciones y fundaciones religiosas (con amplia y contrastada experiencia en la misión del adoctrinamiento patriótico-religioso) en la tarea de «modelación» de un nuevo tipo de español, sirviéndose para ello de unas prácticas autoritarias, jerárquicas y disciplinarias.

A pesar de que las agencias educativas estaban configuradas en una dirección monocorde, con un objetivo claro y definido, alejado de la autocrítica, obediente a las verdades incuestionables (patria y tradición), tuvieron otros apoyos inestimables. A la educación institucional se le suma un importante flujo comunicativo trasmitido de manera informal, prácticamente invisible, pero que permea y es altamente efectivo en la conformación del ideal infantil-adolescente que le conecta con la línea de futuro, modelando los adultos que necesitará la «Nueva España». Inscribamos en este ámbito la acción ejercida por la lectura de «historietas amenas y divertidas» para los tiempos no escolares. Con frecuencia en las carteras de los escolares podían encontrarse compartiendo espacio el calepino, la pizarra y el cuadernillo del héroe del cómic preferido.

is Viñao Frago, A.: «La educación en el franquismo (1936-1975)», Educar em Revista, Brasil, Editora UFPR, n. ${ }^{\circ}$ 5I (20I4), pp. 19-35. 


\section{El mapa de opciones}

Nada de lo que sucede en estos años es ajeno a los ojos del Estado. Todo es observado desde un panóptico dominado por la torre escrutadora de la jerarquía del poder. Fernández Sarasola ${ }^{16}$ señala que las publicaciones infantiles y juveniles también fueron objeto de la supervisión ejercida por la censura. El instrumento para el ejercicio del control de lo publicado y publicables arranca de la primera Ley de Prensa de 22 de abril de 1938 , cuya redacción se debe Giménez-Arnau, a la sazón director general de Prensa en el Ministerio de Gobernación.

Pero el control específico se produce a través de un Decreto que se dicta el 24 de junio de ese mismo año. Mediante ese Decreto se someten a supervisión las publicaciones infantiles y juveniles. En la misma fecha una Orden del Consejo de Ministros establece el trámite de autorización previa a cualquier propuesta editorial destinada a los niños fijando con minuciosa precisión y hasta el mínimo detalle los contenidos excluidos y censurables.

En inicio, si los trabajos censores pudieran encontrar alguna dificultad en la justificación sobre el bloqueo a una publicación, bien en la forma o en el contenido, se contó con otro mecanismo indiscutible para seguir manteniendo el control. En esa España donde se recurría con mucha frecuencia al «estraperlo» para obtener los productos tanto de consumo ostentoso como de primera necesidad, había otros para los que era difícil burlar las restricciones, y el papel de prensa era uno de ellos. El bloqueo y la restricción de papel hizo que su obtención y su utilización se convirtiera también en un fácil instrumento de censura. Ese bien escaso estaba subvencionado por el Estado y los gestores estatales eran quienes concedían los cupos de papel ${ }^{17}$. De nada sirven la imprenta, los tipos y los dibujantes si las planchas no disponen de papel para imprimir. Tener cupo de papel es el premio en «justa» correspondencia al plácet de lo que en él se dice y de cómo se dice. A todos no se les distribuía por igual, ni siquiera de manera proporcional. La asignación de cupo obedecía a razones de Estado y, por ello, un conjunto de cómics $^{18}$ gozaba de la mejor de las disposiciones para satisfacer las necesidades técnicas para su publicación.

Posteriormente, 2i de enero de 1952, la Junta Asesora de la Prensa Infantil, a la que se había dotado de competencias, dictó unas clarificadoras «Normas sobre la prensa infantil» que indicaban los contenidos «admisibles» para las publicaciones destinadas a la infancia.

16 Fernández Sarasola, I.: La legislación sobre historieta en España. Desde sus orígenes hasta la actualidad, Sevilla, Асут Ediciones, 2017.

${ }_{17}$ La disposición de papel se clasificó en tres categorías: el papel prensa (subvencionado), que con precio relativamente barato era asignado en lotes al Estado; el papel revista, que gozaba también de subvención, pero había que acudir al mercado, y el papel de edición (libros), acuciado por la escasez se debía acudir al mercado para su adquisición.

${ }_{18}$ Sin el menor sonrojo los cuadernillos de Flechas y Pelayos, Maravillas, la Biblioteca Maravillas, Clarín, Chicos, o Mari, Bazar (edición patrocinada por Sección Femenina de FET y de las jons), tenían la mejor rampa de acceso para el acceso al papel necesario. 
LOS CÓMICS EN LA CONSTRUCCIÓN DE LA PROPUESTA EDUCATIVA

EN EL PRIMER FRANQUISMO

JOSÉ CARLOS SANCHIDRIÁN FERNÁNDEZ

A esa decantación de contenidos se llegó por medio de la exitosa experiencia acumulada. Entre los antecedentes próximos se contaba con el buen resultado de una de las primeras intervenciones llevadas a cabo en 1937 por la Delegación Nacional de Prensa y Propaganda de Falange Española, que luego fue corroborada en 1938 por los Servicios de Prensa y Propaganda del Estado. Se trata de un proceso por el que se concentra y convierte toda la prensa en prensa del Movimiento. El ejemplo significativo, por lo que aquí nos interesa, es el que afectó a la desaparición ${ }^{19}$ del semanario Pelayos. Esta era una publicación infanto-juvenil que gozaba de una de las mayores tiradas. Había sido llevada al escenario de las lecturas infantiles en el ámbito del pensamiento tradicionalista, alentada e impulsada por la Iglesia navarra, cuyos contenidos no le eran ajenos al tradicionalismo. Haciendo uso de las prerrogativas que le confería la ley, los Servicios de Prensa y Propaganda hicieron que los exitosos cuadernillos de Pelayos aceptaran el cortejo de otra publicación más obscura: Flechas, de ideología marcadamente falangista, dando como resultado una nueva publicación: Flechas y Pelayos $^{20}$. Se encargó la trayectoria editorial de la híbrida publicación al fraile benedictino Justo Pérez de Urbel ${ }^{21}$. El fraile logra bajo su dirección introducir la prevalencia del matiz católico a una publicación en la que confluían ya el falangismo y el pensamiento tradicionalista.

A partir de 1952 parece abrirse un nuevo horizonte. Hay un cierto relajo en lo relativo a los permisos de edición y la obtención de papel fue más fácil. Al sustituir la Vicesecretaría de Educación Popular de FET y de las Jons por la Dirección General de Prensa del Ministerio de Información y Turismo, las publicaciones encuentran un espacio más favorable. Las nuevas condiciones económicas abren la puerta a nuevas editoriales.

Manuel Fraga en el 1966 con su Ley de Prensa pretende tunear con trazos de modernidad una disposición que había quedado superada por las circunstancias sociopolíticas del momento. Se trata de un intento de aggiornamento para las referencias internacionales de un país que trata de abrirse paso, pero la esencia de la reforma consiste en lo mismo: el mantenimiento de la censura y de los censores en el mismo sitio que habían estado. Un años después, en 1967, se publica el Decreto 195/1967, de I9 de enero, que, lejos de suprimir el control ministerial para las publicaciones infantiles, lo mantuvo e incluso fue más preciso en cuanto a los contenidos publicables ${ }^{22}$.

19 Andrés-Gallego, J.: «La muerte de Pelayos y el nacimiento de Flechas y Pelayos (1938)»: Rev. La Iglesia en la Encrucijada. Hispania Sacra, 49 (1997), Madrid, csic.

${ }_{20}$ En esta publicación, que se vendía por 35 céntimos, generalmente aparecían niños vestidos con uniformes fascistas y carlistas mientras que a los «rojos» se les dibujaba como grotescos piratas.

${ }_{21}$ La notable trayectoria del fraile le llevó desde su nombramiento como consejero nacional del Movimiento y procurador en Cortes hasta su investidura en 1958 como primer abad de la Basílica de Santa Cruz del Valle de los Caídos.

22 Fernández Sarasola, I.: La legislación sobre historieta en España. Desde sus orígenes hasta la actualidad, op. cit. 


\section{Los cuadernillos entre los cuadernos}

Una parte de la población infantil durante los primeros años del franquismo había visto la guerra de cerca. En sus retinas se conservaban aún las imágenes y el sonido del conflicto, en las cabezas infantiles se anotaban ausencias y frente a los titubeos para elegir el camino de ponerse a salvo, se ofrecía otra línea cierta y asertiva que permitía recobrar cierta tranquilidad para el transcurso de la cotidianidad. Ir a la escuela para muchos fue el regreso a la vida normal, a la seguridad. Esa escuela estaba patroneada por iconos ganadores. En la pared, al frente, recogiendo la primera mirada de la mañana aparecía la foto del «caudillo» victorioso, de José Antonio y de alguna imagen de santos o santas. Si no fuera por el hambre... Estos niños ahora escolarizados deben aprovechar la magnífica oportunidad para ser instruidos de manera que su generación pueda ganar el futuro. No se podía desaprovechar el viento favorable para instruir con planes de estudio adecuados. Ante las muchas carencias programáticas, fue frecuente que la escuela primaria ${ }^{23}$ siguiera el guion marcado por unos textos escolares que hubieran superado todos los filtros y que ofrecieran un enfoque «sano» fuera de interpretaciones de los contenidos escolares. Esa labor la desarrollaron las «Enciclopedias» y entre ellas la que gozó de más difusión fue la Enciclopedia Álvarez (dividida en varios grados) que proponía aprender de memoria contenidos de Historia de España, Historia Sagrada, Evangelios, Lengua Española, Aritmética, Geometría, Geografía, Ciencias de la Naturaleza, Formación Familiar y Social, Higiene.

La escuela primaria encontró un magnífico guion, pero la oportunidad instructivo-educativa tenía a los io años una decisión transcendente que tomar: hacer el examen de ingreso para cursar el bachillerato o continuar la escolaridad especial hasta los I2 años, para los niños que habían optado por ingresar inmediatamente en el mundo laboral.

De manera paralela, la educación-instrucción constituida por materias utilizables para la vida social, comercial o laboral se acompañaba con otro conjunto de contenidos de claro corte educativo-ideológico formados por las disciplinas transversales con desarrollo obligatorio en todos los niveles educativos. El tronco central de estas materias lo constituyen la religión católica (historia de la religión y catecismo) impartida por sacerdotes y la Formación del Espíritu Nacional que junto con la Educación Física eran impartidas por integrantes del Frente de Juventudes (o de la Sección Femenina si eran chicas).

Podría haber bastado con estas intervenciones para asegurarse la transmisión de los valores que interesaban al Estado fascista del primer franquismo. Pero no fue así, el control, como ya ha quedado dicho, se extendió en todo el ámbito de la relación social; también en los tiempos de «ocio infantil». Y, así, la mirada llegó a las pequeñas publicaciones que cohabitaban con los cuadernos escolares y que eran objeto de lectura o de trueque en los patios de recreo de las escuelas.

${ }_{23}$ La enseñanza primaria no fue objeto de tratamiento legal hasta la aparición ( $B O E$ de $18-7-1945$ ) de la Ley del I7 de julio de 1945 sobre la Educación Primaria. 
LOS CÓMICS EN LA CONSTRUCCIÓN DE LA PROPUESTA EDUCATIVA EN EL PRIMER FRANQUISMO

JOSÉ CARLOS SANCHIDRIÁN FERNÁNDEZ

Antes de entrar en el contenido de imágenes y texto hubo una primera decisión que afectó al formato. El aspecto exterior de los cuadernillos no escapó al control de la censura franquista. Según Vázquez de Parga ${ }^{24}$ el código transmitido a las editoriales, entendible desde la óptica directivista y paternalista, permitía orientar al lector y facilitaba la tarea de filtraje selectivo que necesitaba el censor. De esta manera se habilitaron dos tamaños de cuadernillos. Uno, apaisado ${ }^{25}$, destinado a los niños y jóvenes; mientras que el segundo formato, vertical, estaba destinado a las «historietas» dedicadas a los adultos. Es posible suponer también razones relacionadas con la técnica impresora y económicas ligadas a la optimización de la superficie de papel utilizada.

A pesar de las restricciones de contenidos, de logística o técnicas, contar con una cierta tradición de publicaciones y un cierto arraigo en los lectores en el ámbito urbano, constituyeron antecedentes importantes para facilitar la decisión de las empresas editoriales para reeditar los cuadernillos.

En España la lectura de tebeos había contado con unas publicaciones homologables a la mayor parte de los países europeos. El antecedente más remoto lo encontramos en 1904, año en el que se publica en lengua catalana Patufet. En 1917 la revista infantil más importante era TBO. En I92I se publicaba Pulgarcito, Pinocho (1925), Pocholo (1931) y Chicos (1938).

Son «historietas» que en estos años se las reviste con algunas notas identificativas. Es común que se dibujen personajes-héroes que desarrollan aventuras, en escenarios diversos y en tiempos históricos en los que la idea de «nosotros» era mucho más excelsa. Se narran con una dialéctica y contenidos moralizadores en las que es fácil identificarse con ellos. El personaje-héroe representa la justicia, el bien, la audacia, a la vez que se impregnan de la prudencia y el amor los cómics destinados a las chicas (ideales adscritos a la feminidad imperante).

En la posguerra y poco a poco, pero incesantemente, podemos ver cómo a lo largo de unos pocos años regresan nuevos títulos para personajes que permanecían en el recuerdo de algunas familias.

Por orden cronológico ${ }^{26}$, en 1940 comienza a publicarse Roberto Alcázar y Pedrín, cargado de ideología fascista. En 1944, El Guerrero del Antifaz (con una atractiva remoción del formato). En 1947 vuelve a estar disponible Pulgarcito. Le siguen en 1949 Zipi y Zape, Las hermanas Gilda, o en 1951 El Repórter Tribulete. En 1956 El Capitán Trueno y El Jabato en 1958.

$\mathrm{La}$ «historieta» de cada personaje fue dibujada con arreglo a unas características, a unos valores y situada en el tiempo histórico ${ }^{27}$ en el que cada editorial

24 Vázquez de Parga, S.: Los comics del franquismo, op. cit.

${ }_{25}$ Las medidas del cuadernillo apaisado, $3 \mathrm{I} \times 2 \mathrm{I} \mathrm{cm}$, es un modelo derivado de las publicaciones italianas de los años treinta.

26 Martín, A.: Historia del cómic español: 1875-1939, Barcelona, Gustavo Gili, 1978. Apuntes para una historia de los tebeos, Barcelona, Glénat, 2000.

${ }_{27}$ Lladó, F.: Los cómics de la transición (El boom del cómic adulto 1975-1984), Barcelona, Glénat, 20or, basándose en lo que fue su tesis doctoral reelabora el análisis donde se explica el éxito y fracaso del cómic adulto, alguna de ellas aplicables a los cuadernillos juveniles. 
entendió como el más eficaz para dar respuesta al beneficio económico que se necesitaba, pero sin olvidar que cada nuevo cuadernillo tenía que moverse fina y delicadamente entre lo publicable y lo censurable.

Rodeados de estas características, algunos de estos cómics ${ }^{28}$ narraron aventuras de sus personajes de manera convincente y atractiva hasta conseguir magníficas posiciones en la parrilla de salida de la aceptación infanto-juvenil.

Entre los de especial significación se encuentra Roberto Alcázar y Pedrín. La publicación ${ }^{29}$ auspiciada por el editor Juan Bautista Puerto, propietario de la Editorial Valenciana, cuenta con la creación del viñetista Eduardo Vañó Pastor. La vida de este personaje se extiende en los quioscos hasta el año 1976, habiendo publicado un total de r.219 cuadernos. Se trata de una «historieta» inspirada en el personaje fascista italiano llamado «Dick Fulmine». Roberto Alcázar inicia una descripción de las características prototípicas para los varones que más tarde serán seguidas por otras publicaciones. Lo específico de Roberto Alcázar es que se trata de una ideal representación de un varón adulto que, aunque no tiene una profesión muy bien definida, sí que representa como nadie la ley, la fuerza, la elegancia, la inteligencia, que impone sus «razones» a los necios y malos, no con la fuerza del argumento sino con los puños.

En las imágenes, en la elegancia, en el vestuario, en las formas sociales... son muchos los autores que encuentran un notable parecido del «héroe» con la representación que se transmitía de José Antonio Primo de Rivera y que presidía, junto con la de Franco, todas las cabeceras de las aulas infantiles.

El personaje se hace acompañar por un niño astuto y pillo que dispone a la vez de una pequeña porra con la que golpear. El acompañante adolescente hace uso de un lenguaje directo y unas actitudes que muestran a los demás niños cómo debe emularse a los adultos.

Sociológicamente, el contenido, la trama de los casos resueltos y la previsibilidad de los resultados de su acción hacen que se piense que iba destinado a segmentos de población populares, poco exigentes y con formación básica.

Para Ramírez Domínguez ${ }^{30}$, el personaje de Roberto Alcázar es la representación del ideal de varón generado por el Régimen. Es ese nuevo hombre «un poco monje y un poco soldado, de buena posición social, defensor de la ley -la propiedad privada- de los estados capitalistas contra espías y conspiraciones de toda laña».

El adolescente Pedrín representa la subsidiariedad y la emulación para aquellos jóvenes que no han hecho la guerra y deben seguir la senda trazada por los mayores, que conocen y saben su destino en la historia.

28 Denholm, J. M.: Catálogo del tebeo en España 1865/1980, Círculo del cómic, 1989 (ampliación de un catálogo de i980 en colaboración con Joan Navarro).

${ }_{29}$ Las aventuras transcurren en unos cuadernos que no superaban las is páginas, grapados en el centro, con un formato apaisado, a una sola tinta y en papel de baja calidad.

30 Ramírez Domínguez, J. A.: «Grupos temáticos del tebeo de aventura en la España de posguerra: Notas para una historia de la iconografía e ideología (y II)», Cuadernos de Realidades Sociales, n. 9 (1976), pp. 87-I50. «El “cómic" femenino en España. Arte y anulación», Cuadernos para el Diálogo, 1975, Madrid. 
LOS CÓMICS EN LA CONSTRUCCIÓN DE LA PROPUESTA EDUCATIVA

EN EL PRIMER FRANQUISMO

JOSÉ CARLOS SANCHIDRIÁN FERNÁNDEZ

Hay que reconocer que no todos los autores se alinean con el contenido de Roberto Alcázar como transmisor de la ideología fascista. Porcel Torrens ${ }^{31}$ afirma que «no existe una sola frase en los mil doscientos diecinueve episodios en los que quede patente esta adhesión de los héroes a esta ideología política».

Es posible que en el texto, en las expresiones o en los diálogos no exista una copia fidedigna de los supuestos expresados en los escritos fascistas (versión italiana o versión española), pero es necesario advertir que la transmisión de la idea autoritaria no tiene que ser necesariamente contenida en un expresión léxica; es más contundente cuando la transmisión se hace a través de la actitud, del ejemplo, del modelo y aquí Roberto Alcázar es un paradigma cerrado y completo del modelo fascista.

Manuel Gago pone en la calle en i944 a El Guerrero del Antifaz $z^{32}$. En este caso el héroe es un converso (nada más contundente que un converso para combatir la antigua fe). El escenario sociológico para desarrollar la buena fama es el espacio y el tiempo de los «moros». Como es fácil de imaginar no se trata de los buenos moros que como ejército expedicionario ayudaron al General en la Guerra de liberación, sino de los otros moros invasores de la península para la traición del rey visigodo.

La descripción que se hace del Guerrero del Antifaz ${ }^{33}$ insiste en una tipificación idealizada y arquetípica de las cualidades que deben adornar a un varón. El personaje aparece con una sólida y musculosa constitución, hábil con la espada y valiente en sus empeños.

Presenta dos notas características que le van bien a la España en la que aparece. Una de ellas es el antifaz, para ocultar su anterior identidad (muchos españoles debieron ocultar su pasado), y la otra es una gran cruz en el pecho que se superpone sobre la media luna, que la oculta, que la opaca y que deja bien a las vistas cuál es la nueva opción tomada. En la España de los 40 la identidad funcional, de la que se debería dar pruebas inequívocas de adhesión, ocultaba realidades intelectuales, fe y creencias relegadas al ámbito puramente privado.

La contrafigura ideológica al Guerrero del Antifaz la traza el personaje del Capitán Trueno ${ }^{34}$ (Víctor Mora y Miguel Ambrosio-Ambrós-), personaje guerrero que combate como cruzado en el siglo XII, que protagoniza «aventuras» por todo el mundo haciendo uso de útiles e ingenios aún no inventados para la época en la que se le supone ubicado. Se trata de un arquetipo que representa, en palabras de Víctor Mora (en una entrevista publicada en 20II) ${ }^{35}$, un personaje progresista, subversivo, justiciero, a favor de la democracia y defensor de los débiles.

${ }^{31}$ Porcel Torrens, P.: La historia del tebeo valenciano, Onil, Edicions de Ponent, 2002, pp. II4-II5.

32 vV. AA.: El Guerrero del Antifaz: so años, 2 vols., Valladolid, Ediciones Quirón, 1997.

33 Altarriba, A.: La España del tebeo, Madrid, Espasa, 200I. Los tebeos de la transición, Cuenca, Fundación Antonio Pérez, 2008.

34 Rodríguez, A.: El gran libro de El Capitán Trueno. 50. aniversario, Barcelona, Ediciones B, 2006.

35 Entrevista titulada «Víctor Mora, creador del capitán trueno», publicada en XL Semanal el 25 de septiembre de 2oir por Fernando Goitia. 
El efectista trazo del Capitán Trueno guía toda la serie. Es, esencialmente, el centro de todo un transcurso que se enreda a grados inimaginables accediendo a recursos y técnicas que no conocen límite (incluyendo los más de 50 idiomas que maneja). Su actividad hace conocer a amigos-enemigos agonistas y antagonistas que se toman papeles de aliados amigos de los que algunos mueren y desaparecen como consecuencia del servicio a la buena causa o del trato injusto.

Acompañan al héroe su pareja Sigrid (reina heredera por derecho sucesorio), generosa y valiente; Goliath, y Crispín. Son dos personajes opuestos morfológicamente e intelectualmente, pero unidos profesándose mutua protección sin necesidad de acudir a la obediencia (relación antitética con el autoritarismo imperante).

La narrativa aventurera de Trueno puede que constituya uno de los primeros escritos que, sorteando la censura, se alce de manera crítica contra el franquismo.

El presidente del Círculo de Bellas Artes Juan Miguel Hernández León, en la presentación de la exposición El Capitán Trueno. Tras los pasos del héroe, escribe:

El Capitán Trueno, ese héroe épico de nuestra narrativa popular, que cautivó a varias generaciones de lectores con sus aventuras al tiempo que, inadvertidamente, les inoculaba un hondo respeto por la justicia y un feroz odio a cualquier forma de tiranía que resultaban bastante subversivos en la España del franquismo que le vio nacer.

Algunas circunstancias que introducen estas historietas hacen que realmente sea sorprendente que no fuera directamente bloqueado por el correspondiente Ministerio. En primer término, es sorprendente que la relación entre Trueno y Sigrid (heredera del trono de Thule), con unos cánones de belleza nórdica y apadrinada por pirata, viaje con el héroe sin estar casados. Y aun más extraordinario es el trato amigable que concedía, en numerosas ocasiones, a quienes deberían representar a los enemigos «naturales» por raza o por religión. Trueno toma partido siempre para defender «causa justa» y no reconoce como enemigos o adversarios a aquellos que habían sido señalados por «otros» como los sujetos a combatir sea cual fuere su circunstancia, bandera o religión.

Se estima que en su primera época fue el cuadernillo con mayor difusión semanal, alcanzando la cifra de 350.000 números.

El Jabato asienta su historia también en una tríada de personajes (Taurus y Fideo de Mileto) para representar valores imprescindibles para enfrentarse al mundo: lo valiente, lo fuerte y lo ridículo-medroso.

La lectura permite entrever una ideología asentada en la autoridad que de por sí tienen las clases diferentes a quienes corresponde naturalmente el poder. Hay una jerarquía clasista. Los esclavos y los obreros están para obedecer y servir a los intereses de los que tienen la riqueza (en este caso, para construir el barco de Kuang el Grande, para tratar de conquistar el mundo).

El cómic no podía olvidar el mundo femenino; para las niñas y jóvenes también había una producción específica con contenidos asentados en ese ambiguo concepto de la Educación para la mujer que se promocionaba desde la rama 
LOS CÓMICS EN LA CONSTRUCCIÓN DE LA PROPUESTA EDUCATIVA

EN EL PRIMER FRANQUISMO

JOSÉ CARLOS SANCHIDRIÁN FERNÁNDEZ

femenina del falangismo de la que era precursora y principal adalid Pilar Primo de Rivera a través de la Sección Femenina.

En estos años, como indica Peinado Rodríguez ${ }^{36}$, la moral nacional para la mujer estaba dictada por la Iglesia católica, para quien el marco de relaciones sociales se construía ensalzando los valores derivados de la supeditación, la obligación y la obediencia. Y ¿ cómo no empezar a construir ese futuro para la mujer sin ensalzar suficientemente el mito del amor romántico?

La editorial Toray en 1947 puso a disposición de las niñas unas historias («Azucena») basadas en la tipicidad y el estereotipo de la relación romántica, el afectuosismo y la generosidad.

En la primera época de estos cuadernillos (1946-1950) se publicaron sin numeración. A partir de 1950 fueron historias numeradas, alguna de ellas se publicó en formato vertical y el precio llegó hasta las 2,50 pesetas.

Se debe a Rosa Galceran el éxito de la ilustración de manera que la gestualidad de los personajes tan característica es necesariamente un mérito a reconocer.

Comenzaron siendo cuentos de «hadas» que instalaban la consecución de objetivos para la mujer en la lógica «mágica». El futuro y los sueños de felicidad se detenían en el relato de «príncipes encantadores».

El éxito de estos cuadernillos y también la intención de trazar una frontera que mantuviera separados los temas que debían ser de «chicos» y los de «chicas» permitieron que en años posteriores aparecieran otras publicaciones que abundaban en la misma línea. Florita, Mariló o Claro de Luna estuvieron presentes en los quioscos con más o menos fortuna.

\section{Conclusiones}

Prescindir del pasado como si la historia no hubiera sucedido es un ejercicio arriesgado para cualquier político de largo alcance, como así parece haber sucedido durante las primeras décadas del franquismo, en las que solo se permitió una narrativa sesgada oficiada por algunos de los actores.

A los efectos de la contienda, en extremo graves ya de por sí, habría que sumársele otros de carácter netamente político e ideológico. En la acción política que percutió en la escuela se nutrió de los principios de la Falange y de la vertiente más retrograda de la ideología católica. Simbióticamente vienen a confluir en la censura. Esa censura-control y castigo se constituyó en el ojo para ver lo que sucedía en el tejido social, sin permitir que nada pudiera escapar a él. El censor, el vigilante quiso ahormar todo producto social.

La escuela con que se pretendía atender a una población infantil y juvenil sobre la que se articularia el «Nuevo Estado» era rica en carencias. Se desprendió de las corrientes pedagógicas más vanguardistas a la vez que acopió algunos

36 Peinado Rodríguez, M.: Enseñando a señoritas y sirvientas. Formación femenina y clasismo en el franquismo, Madrid, Catarata, 2012. 
maestros silentes y claramente facciosos. En este contexto, se reanuda la edición de cuadernillos de historietas «cómics» que tratan de proporcionar un modelo a esa juventud-casi niñez que en muchos casos habían visto la guerra de cerca. La conexión que se reestablece con sus antecedentes es más de carácter cronológico que realmente una sucesión lógica de la secuencia narrativa que se venía trazando. Aquellas historietas que habían sido ilustradas durante el primer tercio del siglo ahora quedan sumergidas por la potente maquinaria ideológica del nacionalismo tradicionalista apoyado en las ideas más reaccionarias de la Iglesia católica. 